UDK: 624.012.3/.4

DOI: https://doi.org/10.24867/03CG06Nikolic

\title{
PROJEKAT KONSTRUKCIJE ARMIRANOBETONSKE ZGRADE I ANALIZA INTERAKCIJE SMIČUĆIH ZIDOVA DVA PRAVCA
}

\section{DESIGN OF THE RC STRUCTURE WITH INTERACTION ANALYSIS OF SHEAR WALLS IN TWO DIRECTION}

\author{
Dalibor Nikolić, Fakultet tehničkih nauka, Novi Sad
}

\section{Oblast - GRAĐEVINARSTVO}

Kratak sadržaj - Rad sadrži projekat konstrukcije armiranobetonske zgrade spratnosti $\mathrm{Po}+\mathrm{P}+4$ prema Evrokodovima, kao i analizu interakcije smičućih zidova dva pravca. Proračun je urađen u softverskom paketu Tower 7 i sadrži analizu dejstava, statički $i$ dinamički proračun konstrukcije, dimenzionisanje $i$ planove armiranja karakterističnih pozicija.

Ključne reči: Armiranobetonska zgrada, Evrokodovi, seizmička analiza konstrukcije, smičući zidovi

\begin{abstract}
The paper contains the construction project of reinforced concrete multi-storey building with flooring $U g+G f+4$ according to Eurocode standards and interaction analysis of shear walls two direction. The construction project contains action on structure, static and dynamic analysis, calculations and rebar detailing plan for characteristic position.
\end{abstract}

Keywords: Reinforced concrete building, Eurocodes, earthquake analysis, shear walls

\section{UVOD}

$\mathrm{U}$ radu je prikazan proračun armiranobetonske zgrade spratnosti Po+P+4 sa lokacijom u Obrenovcu.

Analiza dejstava, statički i dinamički proračun, dimenzionisanje i detalji armature urađeni su u skladu sa Evrokod standardom. Na primeru smičučih zidova dva pravca, pozicioniranih $\mathrm{u}$ datom objektu, razmatran je uticaj njihove interakcije na seizmičku otpornost konstrukcije.

\section{TEHNIČKI OPIS}

\subsection{Arhitektonsko rešenje}

Objekat je u osnovi nepravilnog oblika, dimenzija 27,00 $\mathrm{m} \mathrm{u}$ podužnom pravcu i $18,50 \mathrm{~m} \mathrm{u}$ poprečnom pravcu. Projektovan je kao stambeno-poslovni.

Poslovni deo odvojen je u odnosu na stambeni deo i nalazi se u prizemlju. Stambeni deo projektovan je na spratovima sa više različitih stambenih jedinica.

U podrumskom delu predviđena je garaža. Vertikalna komunikacija ostvaruje se pomoću lifta i dvokrakog stepeništa na svim etažama u objektu.

\section{NAPOMENA:}

Ovaj rad proistekao je iz master rada čiji mentor je bio prof. dr Đorđe Lađinović, red. prof.
Fasadni zidovi urađeni su od termo-bloka debljine $25 \mathrm{~cm}$, termoizolacije od mineralne vune $10 \mathrm{~cm}$ i aluminijumskih panela. Unutrašnji zidovi zidani su blokovima debljine $25 \mathrm{~cm}$, dok su pregradni zidovi unutar stanova zidani opekom debljine $12 \mathrm{~cm}$.

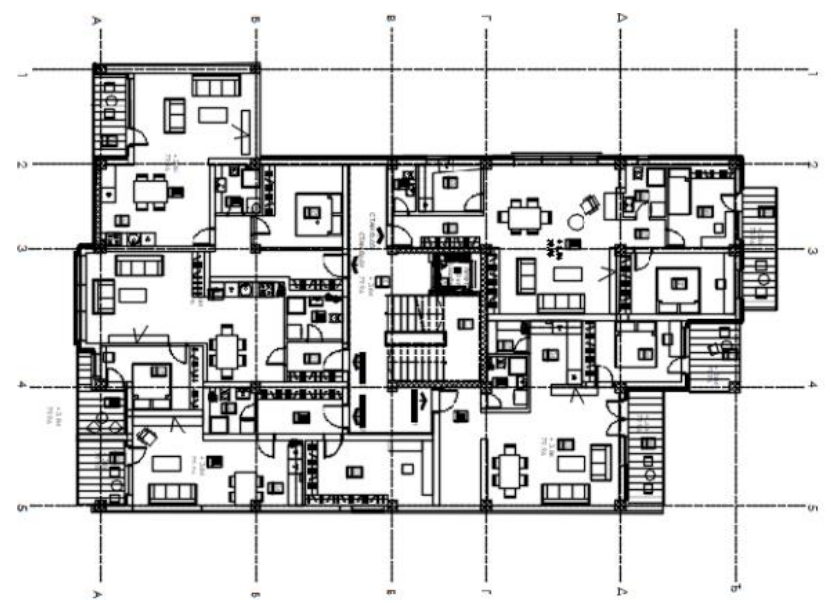

Slika 1. Dispozicija tipskog sprata

\subsection{Konstruktivni sistem}

Konstruktivni sistem je skeletni sa armiranobetonskim platnima za ukrućenje. Vertikalni noseći elementi su AB stubovi dimenzija 40/40, 50/50, 55/55 cm. Skeletnu konstrukciju celom visinom ukrućuju četiri zida debljine $25 \mathrm{~cm}$ - po dva u svakom ortogonalnom pravcu dok je $\mathrm{u}$ središnjem delu konstrukcija ukrućena liftovskim jezgrom debljine $25 \mathrm{~cm}$.

Međuspratna konstrukcija svih etaža je betonska ploča debljine $16 \mathrm{~cm}$. Ploča se oslanja na sistem greda međusobno upravnih i povezanih sa stubovima. Dimenzije greda su $35 / 50 \mathrm{~cm}$.

Stepeništa u objektu su dvokraka, formirana kao kolenaste ploče debljine $15 \mathrm{~cm}$. Oslanjanje stepeništa je na grede.

Temeljenje objekta je na temeljnoj ploči debljine $50 \mathrm{~cm}$ uz usvajanje koeficijenta posteljice od $\mathrm{Ks}=10000$. Oslanjanje stubova je direktno na temeljnu ploču te se $u$ zonama ispod stubova temeljna ploča dodatno armira. Ispod liftovskog jezgra temeljna ploča se dodatno proširuje i armira. Podrumski zidovi izrađeni su od armiranog betona i njihova debljina je $25 \mathrm{~cm}$.

Elementi su armirani rebrastom armaturom B500B, a izrađeni od betona klase C30/37 i C35/45. 


\section{ANALIZA OPTEREĆENJA}

Analiza opterećenja urađena je prema evropskim standardima [3], [4], [5] i obuhvata stalno opterećenje, korisno opterećenje, opterećenje vetrom, opterećenje snegom i seizmičko opterećenje.

\subsection{Stalno opterećenje}

Stalnim opterećenjem obuhvaćena je sopstvena težina konstruktivnih elemenata, slojeva podova, plafona i zidova. Opterećenje je naneto kao površinsko na međuspratnu konstrukciju, dok je opterećenje od zidova naneto kao linijsko opterećenje.

Intezitet opterećenja međuspratnih konstrukcija prosečno iznosi $1,40 \mathrm{kN} / \mathrm{m}^{2}$.

Opterećenje krovne ploče je $3,70 \mathrm{kN} / \mathrm{m}^{2}$. Opterećenje od tla sračunato je za tlo u stanju mirovanja i iznosi 26,73 $\mathrm{kN} / \mathrm{m}^{2}$.

\subsection{Korisna opterećenja}

Inteziteti korisnog opterećenja prema evropskim propisima [3], prikazani su tabelom 1 .

\begin{tabular}{|l|l|l|l|}
\hline Kategorija & Namena & Pod-kategorija & $q_{\mathrm{k}}\left[\mathrm{kNN} / \mathrm{m}^{2}\right]$ \\
\hline A & Stambene površine & Podovi & 2,00 \\
\hline A & Stambene površine & Stepeništa & 2,00 \\
\hline A & Stambene površine & Balkoni & 2,50 \\
\hline D1 & Prodajne površine-Prizemlje & Maloprodajne radnje & 4,00 \\
\hline Cl & Površine na kojima je moguće okupljanje ljudi & Krov & 3,00 \\
\hline F & Saobraćajne površine & Garaža & 2,50 \\
\hline
\end{tabular}

Tabela 1. Vrednosti korisnog opterećenja

\subsection{Opterećenje snegom}

Opterećenje snegom razmatra se sa intezitetom od 0,80 $\mathrm{kN} / \mathrm{m}^{2}$ na površini krovne ploče.

\subsection{Opterećenje vetrom}

Opterećenje vetrom deluje na konstrukciju pritiskujućim i sišućim dejstvom. Razmatrano je kao površinsko a putem konvertora opterećenja transformisano u linijsko.

\subsection{Seizmičko opterećenje}

Projektnim zadatkom definisano je maksimalno horizontalno ubrzanje tla koje iznosi $\mathrm{a}_{\mathrm{gR}}=0,15 \mathrm{~g}$. Kategorija tla je C, a kategorija značaja II.

Razmatran je prvi tip elastičnog spektra odgovora.

Konstrukcija je projektovana za srednju klasu duktilnosti i ispunjava kriterijume regularnosti u osnovi i po visini.

Prema načinu prenošenja horizontalne sile, konstrukcija se klasifikuje kao zidni sistem u oba glavna pravca. Faktor ponašanja konstrukcije iznosi $\mathrm{q}=3,60$.

Seizmičko opterećenje razmatrano je za dva ortogonalna pravca, za glavni $\mathrm{X}$ i $\mathrm{Y}$ pravac. Prilikom analize seizmičkog dejstva razmatrana je i SRSS kombinacija opterećenja.

Koeficijent prigušenja iznosi 0,05 a slučajni ekscentricitet spratne mase iznosi $\mathrm{Ei}=0,05 \mathrm{xLi}$.

\section{MODELIRANJE KONSTRUKCIJE}

Konstrukcija je modelirana u softveru Tower 7. Proračun je izvršen metodom konačnih elemenata. Svi uticaji u konstrukciji određeni su na prostornom proračunskom modelu. Grede i stubovi modelirani su kao linijski elementi, međuspratne tavanice, krovna ploča, temeljna ploča i smičući zidovi kao površinski elementi. Karakteristike materijala definisane su klasom betona C30/37 i C35/45.

Izgled proračunskog modela prikazan je slikom 2.

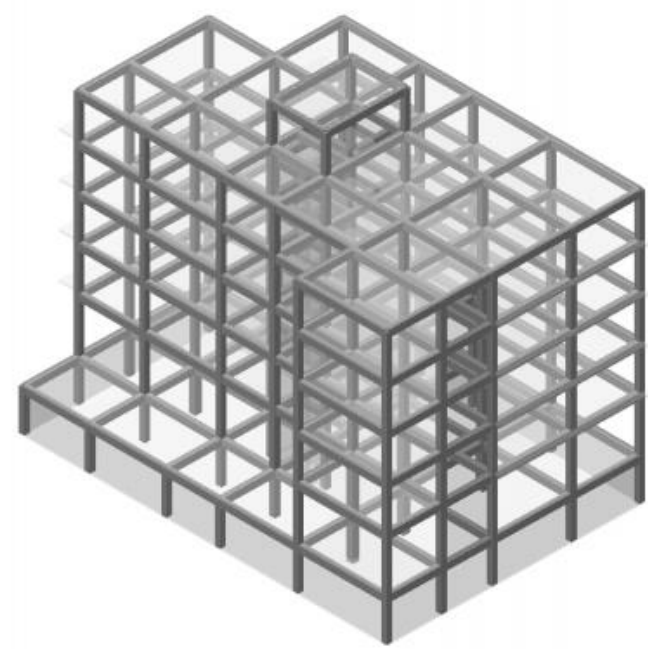

Slika 2. Izgled proračunskog modela

\section{DINAMIČKA ANALIZA}

Dinamičkom analizom konstrukcije određene su svojstvene vrednosti i oblici oscilovanja konstrukcije. Proračun je izvršen putem multi modalne spektralne analize. Prilikom analize mase su koncentrisane u nivou tavanica.

Stalna opterećenja i opterećenje snegom uzimaju se u punom iznosu, dok se vrednosti korisnog opterećenja redukuju odgovarajućim faktorom. Tom redukcijom obuhvata se verovatnoća pojave datog opterećenja u punom iznosu pri seizmičkom dejstvu.

Vrednosti prvih sedam tonova oscilovanja konstrukcije prikazane su tabelom 2.

\begin{tabular}{|c|c|r|}
\hline $\mathrm{No}$ & $\mathrm{T}[\mathrm{s}]$ & $\mathrm{f}[\mathrm{Hz}]$ \\
\hline 1 & 0.7349 & 1.3607 \\
\hline 2 & 0.7025 & 1.4234 \\
\hline 3 & 0.6009 & 1.6640 \\
\hline
\end{tabular}

Tabela 2. Periodi oscilovanja konstrukcije

Narednim slikama prikazano je oscilovanje konstrukcije po tonovima. 


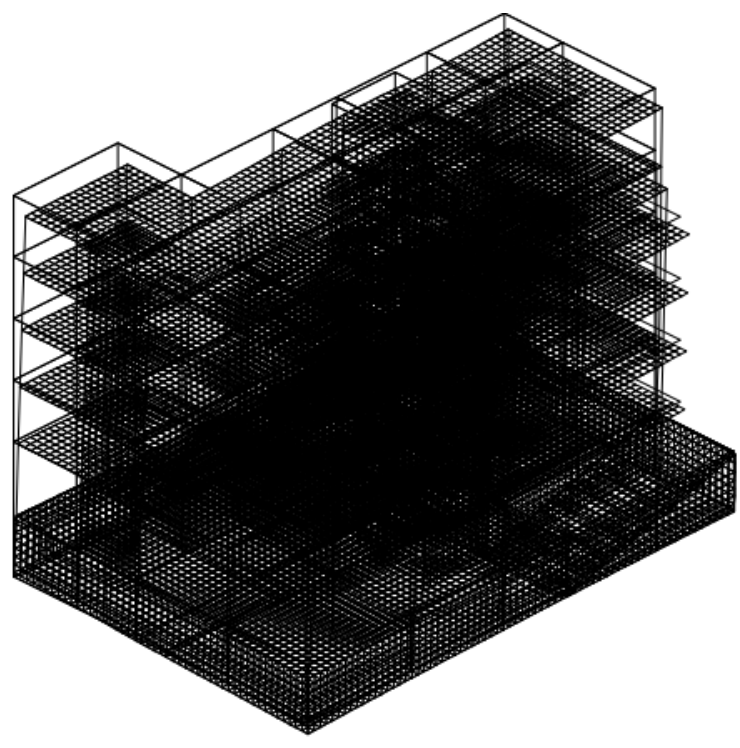

Slika 3. Prvi ton oscilovanja

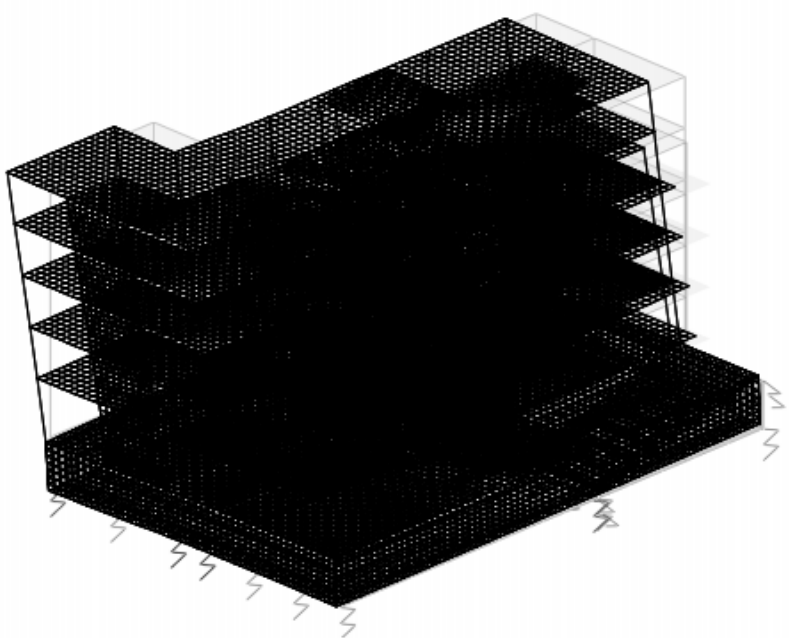

Slika 4. Drugi ton oscilovanja

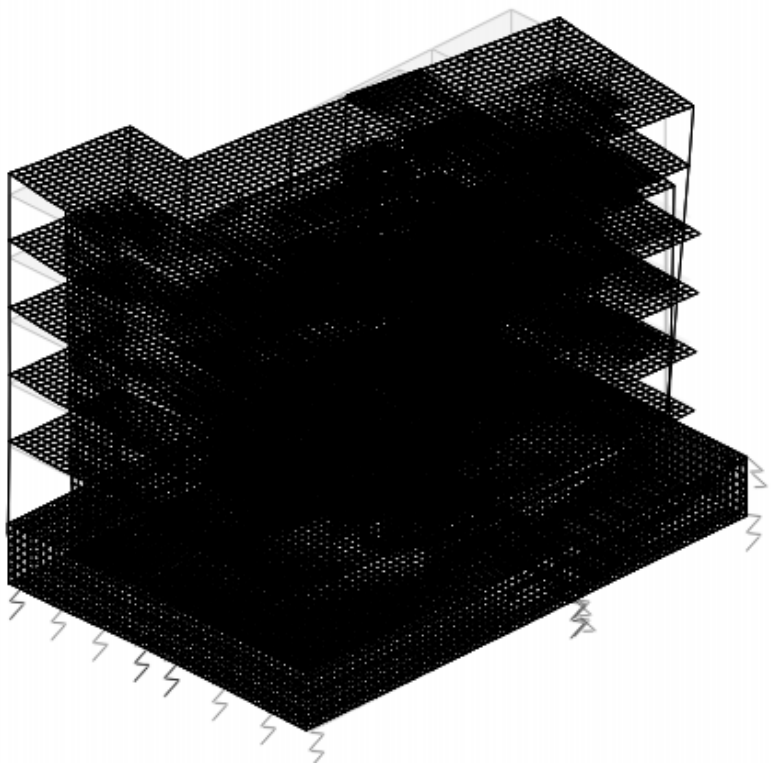

Slika 5. Treći ton oscilovanja

\section{DIMENZIONISANJE}

Proračun prema Evrokodu zasniva se na teoriji graničnih stanja. Razmatrana su granična stanja nosivosti i graniča stanja upotrebljivosti. Pri graničnom stanju upotrebljivosti kontrolisane su prsline i ugibi.

Elementi su dimenzionisani poštujući odredbe Evrokoda 2 i Evrokoda 8. Prema Evrokodu 8, konstrukcija je dimenzionisana sledećim redosledom:

- $\quad$ armatura u pločama

- podužna armatura greda

- podužna armatura stubova

- poprečna armatura greda

- $\quad$ poprečna armatura stubova

Pre dimenzionisanja elemenata izvršene su proračunske kontrole i to:

- Kontrola normalnih sila u stubovima

- Kontrola normalnih sila u zidovima

- Proračun međuspratnih pomeranja

- Obuhvatanje uticaja drugog reda

- Geometrijski uslovi

- Kontrola napona u tlu

- Kontrola temeljne ploče na probijanje

\section{INTERAKCIJA SMIČUĆIH ZIDOVA DVA PRAVCA}

Pored projektovanja samostalnih ortogonalnih smičućih zidova, u konstrukcijama zgrada se često projektuju i spregnuti zidovi. Spregnuti zidovi sastoje se od dva ili više zida koji su međusobno povezani na način da prenose opterećenje zajedničkim radom kao jedinstveni presek. Njihovo spajanje moguće je u ravni i spajanjem u dva pravca.

Pri sprezanju zida dva pravca, formiraju se složeni preseci velikog momenta inercije. Njihova krutost višestruko prevazilazi krutost pojedinačnih elemenata. To se dešava zbog toga što njihova međusobna povezanost ograničava konzolno savijanje pojedinačnih zidova, terajući tako sistem da funkcioniše kao složena celina.

Ovako formirana celina sposobna je da prenese opterećenje iz dva pravca. Najčešći oblici ovako formiranih zidova su L,T i U.

Daljom analizom biće razmatrani zidovi dva pravca na konkretnom primeru armiranobetonske zgrade. Proračunskim modelom razmatraće se ponašanje smičućih zidova kao samostalnih elemenata i uporediti sa rezultatima gde se u proračunskom modelu obuhvata interakcija sa zidom drugog pravca. Ovom uporednom analizom dva modela razmotriće se značaj i doprinos spregnutih zidova na ukupnu seizmičku otpornost zgrade. Narednom slikom prikazani su izdvojeni zidovi koji se analiziraju. 


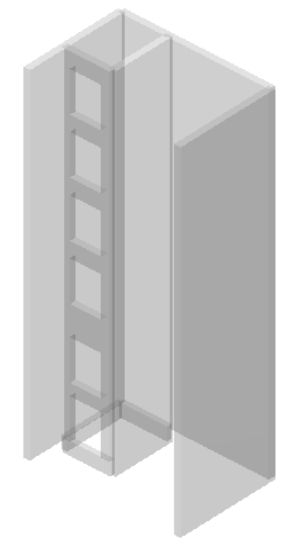

\section{Slika 6. Analizirani smičući zidovi}

Tabelarnim prikazom upoređeni su rezultati proračuna dva modela i procentualno prikazano uvećanje uticaja koje zid prihvata na sebe usled obuhvatanja interakcije zidova dva pravca.

\begin{tabular}{|c|c|c|c|}
\hline \multirow{2}{*}{} & \multicolumn{3}{|c|}{ Ram 3-3 } \\
\cline { 2 - 4 } & $\begin{array}{c}\text { Bez uticaja zida } \\
\text { drugog pravca }\end{array}$ & $\begin{array}{c}\text { Sa uticajem zida } \\
\text { drugog pravca }\end{array}$ & $\begin{array}{c}\text { Procentualna } \\
\text { povećanje uticaja } \\
(\%)\end{array}$ \\
\hline $\mathbf{M x}$ & 6,56 & 6,86 & 4,57 \\
\hline $\mathbf{M y}$ & 15,60 & 16,17 & 3,65 \\
\hline $\mathbf{N}$ & 874,68 & 1523,62 & 74,19 \\
\hline $\mathbf{N y}$ & 1513,98 & 2189,48 & 44,62 \\
\hline $\mathbf{Y} \mathbf{y}$ & 16,68 & 15,15 & 9,17 \\
\hline & \multicolumn{3}{|c|}{ Ramn 4-4 } \\
\hline & $\begin{array}{c}\text { Bez uticaja zida } \\
\text { drugog pravca }\end{array}$ & $\begin{array}{c}\text { Sa uticajen zida } \\
\text { drugog pravca }\end{array}$ & $\begin{array}{c}\text { Procentualna } \\
\text { porećanje uticaja } \\
\text { (\%) }\end{array}$ \\
\hline $\mathbf{M x}$ & 5,60 & 7,67 & 36,96 \\
\hline $\mathbf{M y}$ & 10,95 & 11,65 & 6,39 \\
\hline $\mathbf{N}$ & 1400,53 & 2397,96 & 71,22 \\
\hline $\mathbf{N y}$ & 1873,08 & 2684,70 & 43,33 \\
\hline $\mathbf{Y} \mathbf{y}$ & 17,06 & 16,83 & 1,35 \\
\hline
\end{tabular}

Tabela 3. Rezultati proračuna rama 3-3 i rama 4-4

\begin{tabular}{|c|c|c|c|}
\hline & \multicolumn{3}{|c|}{ Ram D-D } \\
\hline & $\begin{array}{c}\text { Bez uticaja zida } \\
\text { drugog pravca }\end{array}$ & $\begin{array}{c}\text { Sa uticajem zida } \\
\text { drugog pravca }\end{array}$ & $\begin{array}{c}\text { Procentualna } \\
\text { porećanje uticaja } \\
(\%)\end{array}$ \\
\hline $\mathbf{M x}$ & 5,54 & 6,84 & 23,47 \\
\hline $\mathbf{M y}$ & 6,82 & 7,92 & 16,13 \\
\hline $\mathbf{N x}$ & 476,47 & 949,88 & 99,36 \\
\hline $\mathbf{N y}$ & 1393,50 & 3204,20 & 129,94 \\
\hline $\mathbf{Y}$ & 16,20 & 15,93 & 1,67 \\
\hline
\end{tabular}

Tabela 4. Rezultati proračuna rama $D-D$

\section{ZAKLJUČAK}

Proračunom konstrukcije prema Evrokodu 8, uvode se inovacije $u$ proračunskim pristupima i načinu razmatranja smičućih, seizmičkih zidova. Prvenstveno se misli na detaljnije razmatranje i uvođenje mogućnosti proračuna smičućih zidova uz istovremeno razmatranje zidova $u$ dva, međusobno upravna pravca.
Uporednom analizom dva proračunska modela dobijeni su rezultati koji su tabelarno prikazani. Rezultati su zavisni od položaja smičučeg zida u konstrukciji i njegovih dimenzija, što za sobom povlači i različite dimenzije efektivnih širina flanši. Takođe, od uticaja na rezultate je i oblik nastalog efektivnog poprečnog preseka. Analizom rezultata može se zaključiti da za pojedine uticaje dolazi do velikih razlika u rezultatima. Do pojave razlike dolazi jer pri seizmičkom dejstvu u zonama ukrštanja zida dva pravca, dolazi do formiranja složenih preseka zidova koji višestruko prevazilaze krutost pojedinačnih zidova. Veća krutost ovakvog elementa u složenim proračunskim modelima indukuje na sebe i veće uticaje.

Uzimanjem u obzir interakcije zidova drugog pravca pri seizmičkoj analizi konstrukcije realnije se sagledava celokupno ponašanje konstrukcije. Formirani složeni preseci zidova tada $\mathrm{u}$ većoj meri prihvataju na sebe horizontalno seizmičko opterećenje. Ovakvim načinom razmatranja mogu se dobiti manje dimenzije i manji broj smičućih zidova, a samim tim ostvaruju se i višestruke pogodnosti sa arhitektonskog i ekonomskog aspekta.

\section{LITERATURA}

[1] Brujić Zoran: Betonske konstrukcije u zgradarstvu (prema Evrokodu), skripta

[2] Evrokod 0: EN 1990:2002 Osnove proračuna konstrukcija

[3] Evrokod 1: EN 1991-1-1:2002 Dejstva na konstrukcije, deo 1-1: Zapreminske težine, sopstvena težina, korisna opterećenja za zgrade

[4] Evrokod 1: EN 1991-1-2:2003 Dejstva na konstrukcije, deo 1-3: Dejstva snega

[5] Evrokod 1: EN 1991-1-4:2005 Dejstva na konstrukcije, deo 1-4: Dejstva vetra

[6] Evrokod 2: EN 1992-1-1:2004 Proračun betonskih konstrukcija, deo 1-1: Opsta pravila i pravila za zgrade

[7] Evrokod 8: EN 1998-1-1:2004 Proračun seizmički otpornih konstrukcija, deo 1-1: Opsta pravila, seizmička dejstva i pravila za zgrade

\section{Kratka biografija:}

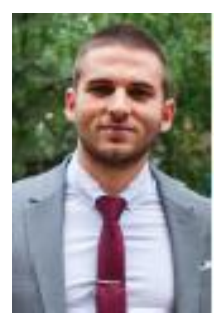

Dalibor Nikolić rođen je u Sremskoj Mitrovici 1994. god. Master rad na Fakultetu tehničkih nauka iz oblasti Građevinarstva Betonske konstrukcije, odbranio je 2018.god.

kontakt: ndalibor94@gmail.com 